\title{
Patterning cell using Si-stencil for high-throughput assay
}

\author{
Jinbo Wu, ${ }^{a}$ Mengying Zhang, ${ }^{a}$ Longqing Chen, ${ }^{b}$ Vivian Yu ${ }^{c}{ }^{\text {Joseph Tin-Yum Wong }}{ }^{c}$ Xixiang Zhang, ${ }^{b}$ Jianhua \\ Qin $^{d}$ and Weijia Wen*a
}

Received 27th July 2011, Accepted 29th July 2011

DOI: $10.1039 / \mathrm{c} 1 \mathrm{ra00520k}$

In this communication, we report a newly developed cell pattering methodology by a silicon-based stencil, which exhibited advantages such as easy handling, reusability, hydrophilic surface and mature fabrication technologies. Cell arrays obtained by this method were used to investigate cell growth under a temperature gradient, which demonstrated the possibility of studying cell behavior in a high-throughput assay.

Most cell processes in vivo are controlled by microenvironmental stimuli, which include neighboring cells, extracellular matrices, soluble factors and physical forces. ${ }^{1}$ Complex signals such as these cannot adequately be manipulated by conventional cell-culture methods. Over the past few years however, microscale technologies have emerged as powerful tools for realizing this complexity, ${ }^{2}$ providing not only precise cell control and reagent distribution, ${ }^{3-5}$ but also a high-throughput assay. ${ }^{6}$ Therein, cell patterning has been used as an effective experimental method to create two or threedimensional biological structures for studying cell interactions and artificial organs in vitro. ${ }^{7-9}$

Micropatterned cell structures have been achieved by means of inkjet printing, ${ }^{10,11}$ micropatterned surfaces, ${ }^{12-15}$ microfluidics, ${ }^{16-18}$ and stencils. ${ }^{19-22}$ The microfabricated stencil, in fact, is a useful and simple approach that obviates the multi-step fabrication required to produce micropatterned surfaces. ${ }^{23}$ Stencils, as noted in previous reports, can be made from stainless steel, ${ }^{21}$ Norland Optical Adhesive $73,{ }^{24}$ PDMS, ${ }^{25-27}$ or parylene. ${ }^{7,19}$ Hard materials are seldom used, on account of the complicated fabrication processes involved and their inability to seal effectively to surfaces. ${ }^{19}$ Nonetheless, in this paper, we present a facile methodology for cell micro-patterning which employs silicon-based stencils (Si-stencils). The Si-stencil provides the advantages of an inert and hydrophilic surface, reusability, and easy handling. Moreover, well developed semiconductor techniques facilitate the microfabrication of highresolution, reproducible Si-stencils. The cell pattern formed with our

${ }^{a}$ The Department of Physics and KAUST-HKUST Micro/Nanofluidic Joint Laboratory, The Hong Kong University of Science and Technology, Clear Water Bay, Hong Kong. E-mail: phwen@ust.hk; Fax: 852

23581652; Tel: 85223587979

${ }^{b}$ Advanced Nanofabrication, Imaging and Characterization Core Lab, King Abdullah University of Science and Technology, Thuwal 23955-6900, Kingdom of Saudi Arabia

${ }^{c}$ Division of Life Science, The Hong Kong University of Science and Technology, Clear Water Bay, Hong Kong

${ }^{d}$ Dalian Institute of Chemical Physics, Chinese Academy of Sciences, 457, Zhongshan Road, 11603, China improved methodology showed that the Si-stencil offers flexibility and wide applicability, from large-scale cell patterns all the way down to the single-cell level.

Additionally, in the present study, we integrated a twodimensional cell array patterned by the Si-stencil with a temperature gradient of $10{ }^{\circ} \mathrm{C}$. This type of integrated device allows for multiple analyses on a single device in combinatorial fashion: different temperatures, with different cell-growth results. The cell-growth results demonstrated that the device can be used to study either cell behavior or cellular communication in high-throughput assay.

\section{Experimental section}

Si-stencils were fabricated using two common MEMS techniques: photolithography and dry etching. The process is schematized in Fig. 1a. The starting material was a double-side polished Si wafer of $400 \mu \mathrm{m}$ thickness. The wafer was patterned with a photoresist (PR) using photolithography, and subsequently dry etched on the front side by inductively coupled plasma-deep reactive ion etching (ICPDRIE). The same process was repeated on the back side so as to generate a hole array through the wafer prior to removal of the PR. The full wafer was then baked in a furnace in order to grow a $200 \mathrm{~nm}$ thermal Si oxide layer on the surface for passivation, after which, finally, it was cut into stencils. The Si-stencils, with a pattern area of $100 \mathrm{~mm}^{2}$ and with hole diameters $\left(\mathrm{D}_{\mathrm{h}}\right)$ ranging from 8 to $400 \mu \mathrm{m}$, were cleaned with piranha solution $\left(\mathrm{H}_{2} \mathrm{SO}_{4}: \mathrm{H}_{2} \mathrm{O}_{2}=10: 1\right)$ at $120{ }^{\circ} \mathrm{C}$ for $10 \mathrm{~min}$ and rinsed with DI water. Fig. $1 \mathrm{~b}$ is a scanning electron micrograph of one of the Si-stencils. The $\mathrm{D}_{\mathrm{h}}$ in this case is $13 \mu \mathrm{m}$. In

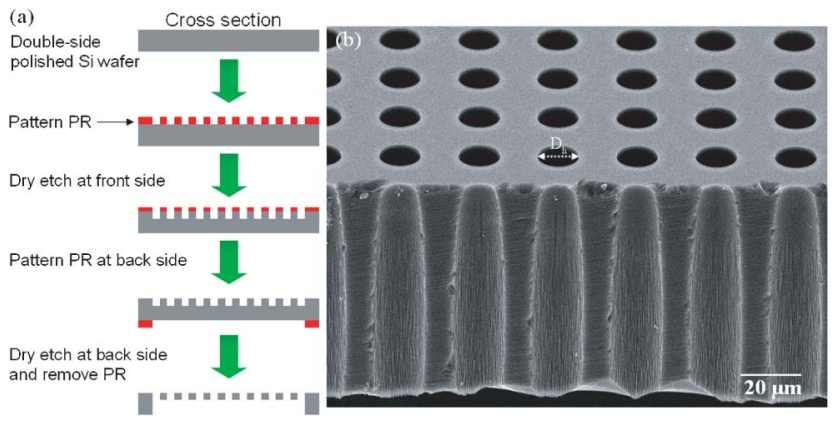

Fig. 1 (a) A process flow diagram illustrating the fabrication procedure of the Si-stencil using two MEMS techniques. Detail description of the steps is in the text. (b) Scanning electron micrograph of a Si-stencil with $13 \mu \mathrm{m} \mathrm{D}_{\mathrm{h}}$. The Si-stencil was cut through the holes to reveal its cross section. 
the cross-section view, the microchannel is $\sim 70 \mu \mathrm{m}$ in length (the thickness of the Si-stencil in the area of the hole array) and of funnel shape, with upper and lower diameters of $13.5 \mu \mathrm{m}$ and $16.9 \mu \mathrm{m}$, respectively. Since the upper surface was attached to the culture dish, such a funnel shape could not affect the cell patterning, and in fact, the upper diameter $(13.5 \mu \mathrm{m})$ is regarded as effective.

We used HeLa cells to examine the Si-stencils preparatory to the cell array. The cells, derived from cervical cancer cells, were obtained from the American Type Culture Collection (ATCC; Manassas, VA, USA). They were cultured, in Minimum Essential Medium supplemented with $10 \%$ fetal bovine serum (FBS), 100 unit $/ \mathrm{mL}$ penicillin and $100 \mathrm{mg} \mathrm{mL}^{-1}$ streptomycin, at $37{ }^{\circ} \mathrm{C}$ in a $5 \%-\mathrm{CO}_{2}$-humidified incubator. For routine culturing, cells were passaged every 1-2 days to maintain the confluency at approximately $85 \%$. For sub-culturing, the cells were washed with pre-warmed phosphate-buffered saline (PBS) and then detached from the substrate by treatment with prewarmed $0.25 \%(\mathrm{w} / \mathrm{v})$ trypsin. When the cells were detached from the dish, fresh culture medium was added. The cell number was estimated prior to the cell culture.

The Si-stencils were each sterilized by UV light on both sides for 15 min before use. As shown in Fig. 2a, a drop of culture medium without HeLa cells was attached to the bottom of the culture dish prior to cell loading. Then, a Si-stencil was pressed onto the drop in order to fill its hole array with culture medium and, thereby, prevent air-bubble formation during cell loading. To maintain pressure sufficient to keep the stencil attached to the dish bottom, a pressed polydimethylsiloxane (PDMS; Dow Corning Corporation) frame was positioned between the stencil and the cover of the dish, and the cover was fixed to the dish by tape. After loading onto the stencil, the

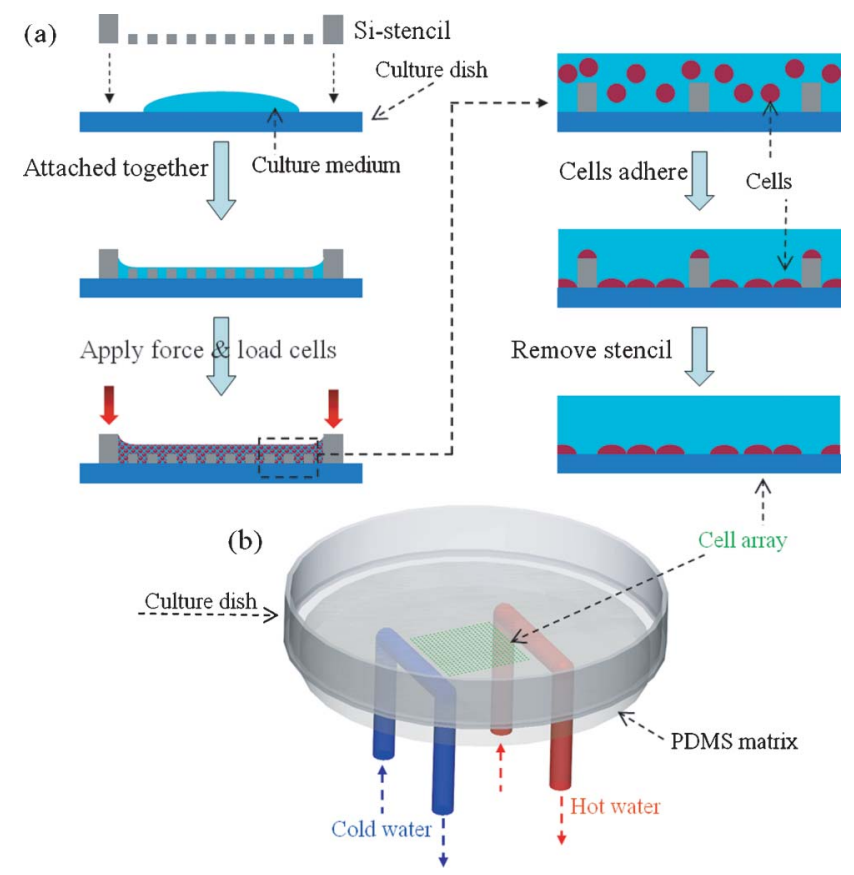

Fig. 2 (a) Schematic illustration of patterning cell on culture dish by the Sistencil. See text for details. For better view, the last three steps were enlarged to see the cells. (b) 3D view of the experimental setup for creation of thermal gradient (not to scale). Cold and hot water flow through the blue and red U-shaped tube, respectively. Both tubes were attached to the bottom of culture dish by the PDMS matrix. In the centre of the culture dish, there was a cell array shown in green color. cells were allowed to spread and adhere to the culture dish through the holes for $5 \mathrm{~h}$ in an incubator. Then, the stencil was removed and the culture dish was washed twice with culture medium to remove unattached or poorly attached cells.

Two parallel U-shaped steel tubes (inner diameter $[\mathrm{ID}]=0.7 \mathrm{~mm}$, outer diameter $[\mathrm{OD}]=1.1 \mathrm{~mm}$, hereafter U-tubes) positioned $12 \mathrm{~mm}$ apart were fixed in the PDMS matrix. The matrix was then attached to the backside of the culture dish (Fig. 2b, not to scale), in the centre of which was the Si-stencil-produced $10 \mathrm{~mm} \times 10 \mathrm{~mm}$ cell pattern (shown in green color). Cold and hot water is circulated in two independent closed circuits (not shown in Fig. 2b) through the two U-tubes respectively, by means of two peristaltic pumps (EW-77120-52, C/L, Masterflex) and two reservoirs. The U-tubes permit fast heat transfer to/from the culture dish, after which hot/ cold water flows back to the hot/cold water reservoirs. The water temperature in the hot water reservoir is maintained by a temperature controller (KT4, Panasonic), while that in the cold water reservoir is kept at room temperature by an air-conditioner. The temperature difference between the two U-tubes creates a thermal gradient across the culture dish.

In order to determine the quality and uniformity of the temperature gradient, an infrared (IR) camera (Thermalvision A40 M, FLIR Systems Inc.) was employed to detect both the thermal distribution and the local temperature. After the cold and hot flows were initiated, about $30 \mathrm{~min}$ was required to establish a steady gradient $\left(25-35^{\circ} \mathrm{C}\right.$ ). The temperature was monitored every $10 \mathrm{~min}$ for $2 \mathrm{~h}$; the fluctuation observed was on the order of $\pm 1{ }^{\circ} \mathrm{C}$. Once the temperature gradient was established, the culture dish with the cell array was attached to the PDMS matrix. The entire setup was maintained in a $5 \%-\mathrm{CO}_{2}$-humidified chamber. Phase-contrast images of the cell array, at four positions along L1 direction, were taken every $6 \mathrm{~h}$ as subject to the thermal gradient effect.

\section{Results and discussion}

As a hard material, the Si-stencil is prone to the same drawback as any metallic stencil: it does not seal well against the substrate and, therefore, cannot guarantee that a cell suspension does not spread beyond the hole area, which fact limits its application to very dilute cell suspensions. ${ }^{21,25}$ To overcome this obstacle, in the present study the Si-stencil was pressed close to the substrate (culture dish) during cell patterning. Cell-suspended media of $1 \times 10^{5} \sim 10^{7}$ cells ml $^{-1}$ concentrations was used to test our methodology. Fig. 3a-d show the cell-pattern results for the $1 \times 10^{7}$ cells $\mathrm{ml}^{-1}$ concentration with different $\mathrm{D}_{\mathrm{h}}$. Even at such a high concentration, no cell was found to have spread beyond the hole area.

The metallic stencil has another drawback: the difficulty of fabricating metallic stencils with $\mathrm{D}_{\mathrm{h}}$ on the order of a single cell $(\sim 10$ $15 \mu \mathrm{m}) .{ }^{25}$ However, thanks to the availability of well developed fabrication processes in MEMS, Si-stencil hole arrays can be fabricated easily with $\mathrm{D}_{\mathrm{h}}$ down to $8 \mu \mathrm{m}$, and moreover, both thickness and $\mathrm{D}_{\mathrm{h}}$ can be individually varied. Moreover, mature fabrication processes and the well established product line in MEMS technologies allow for the mass-producibility, low cost of the Si-stencil and even immediate commercial availability to biologists. In the present study, Si-stencils with $\mathrm{D}_{\mathrm{h}}$ in the $8-400 \mu \mathrm{m}$ range were fabricated to test our methodology. The above-noted Fig. 3a-d provide the cellpattern results for $D_{h}=400,150,40$, and $30 \mu \mathrm{m}$, respectively. Additionally, the cell number in a single domain for each $D_{h}$ was 

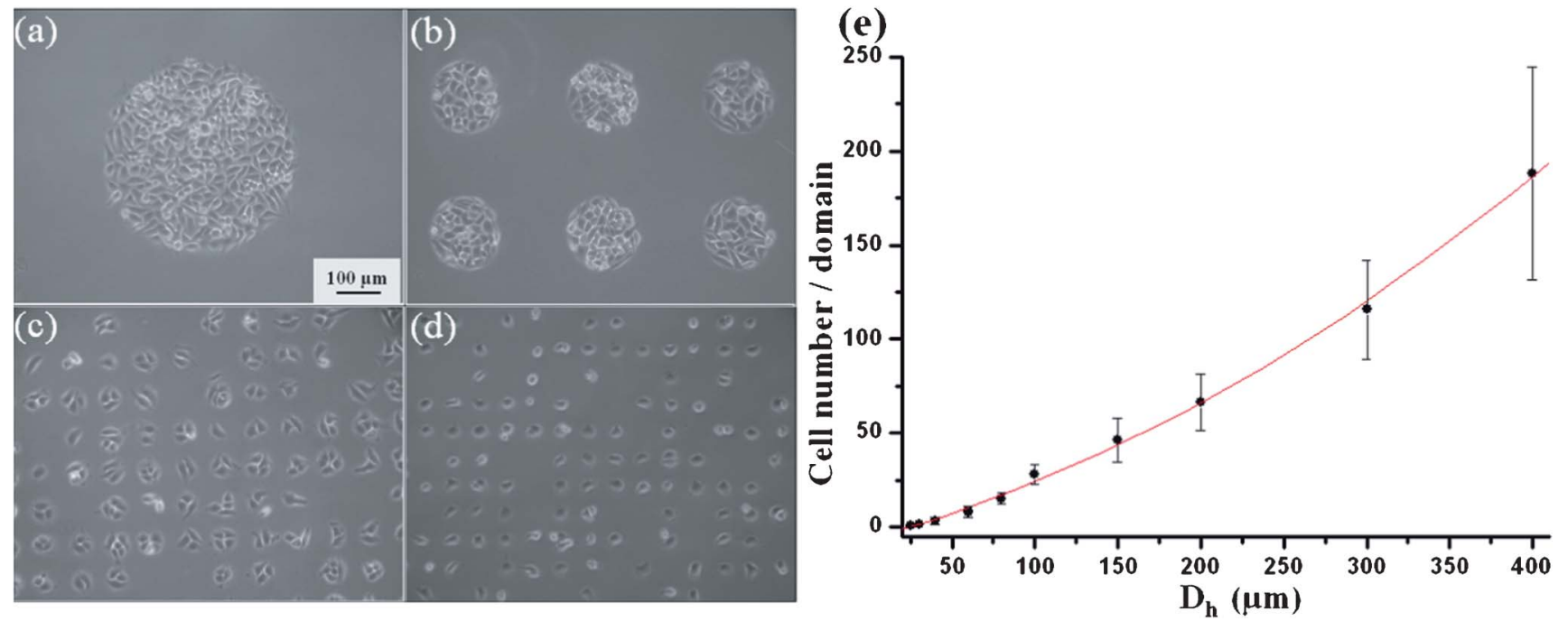

Fig. 3 (a-d) Phase contrast microscopy image of HeLa cell patterned with different $D_{h}$ : $a=400 \mu \mathrm{m}, b=150 \mu \mathrm{m}, \mathrm{c}=40 \mu \mathrm{m}, \mathrm{d}=30 \mu \mathrm{m}$, respectively. All images are at the same magnification. (e) Cell number per domain as a function of $\mathrm{D}_{\mathrm{h}}$. Cells were counted and averaged over 50 domains of each size.

counted, and the data plotted in Fig. 3e as a function of $\mathrm{D}_{\mathrm{h}}$. As is apparent, the $\mathrm{D}_{\mathrm{h}}$ significantly influenced the cell number. When the $\mathrm{D}_{\mathrm{h}}=30 \mu \mathrm{m}$, a single-cell array could be obtained (Fig. 3d). The average percentage of single cells was as high as $60 \%$. Such a singlecell array can be used, further, to study high-throughput cultures in single-cell-level applications including drug-induced apoptosis ${ }^{16,18}$ and cell-cell communication between individual cells.

Compared with the elastomeric stencils, the Si-stencil is rigid, and so handling for alignment and large-area patterning is both possible and easy. ${ }^{25,28}$ Conversely, it cannot, unlike elastomeric stencils, be used on a curved surface. We consider the rigidity of the Si-stencil to be a fundamental limitation.

By contrast with the hydrophobic surface of the polymer stencils, ${ }^{19,23,25}$ the Si-stencil surface (silicon dioxide) is hydrophilic. A low contact angle (about $5^{\circ}$ ) is obtainable after cleaning with piranha solution, so that the culture medium can fill stencil holes easily. This unique advantage avoids the formation of air bubbles that become trapped in the Si-stencil during cell seeding; no additional, air-bubble-removal procedure, then, is needed. In the present study, no air bubbles were found, not even in the Si-stencil with a $D_{h}$ as small as $8 \mu \mathrm{m}$.

Two methods of used-stencil cleaning were trialled: wet cleaning by piranha solution at $120{ }^{\circ} \mathrm{C}$ for $10 \mathrm{~min}$, and dry cleaning by $\mathrm{O}_{2}$ plasma treatment (IPC2000 Photo Resist Asher, Branson) for $30 \mathrm{~min}$. The Si-stencils recovered by either method were then reused for cell patterning, and showed no observable variation. This reusability advantage is owed to the biocompatibility, inertness, smoothness and uniformity of silicon-dioxide-coated Si-stencil surfaces, which minimize adsorption and inhibition. ${ }^{29}$

To demonstrate the cell array has potential application in highthroughput screening, we integrated it with a temperature gradient. Fig. 4a is a thermal image of the culture dish's bottom surface taken when the thermal gradient was stable. The cell array, highlighted by the green square, is located in the centre of the image. Temperatures

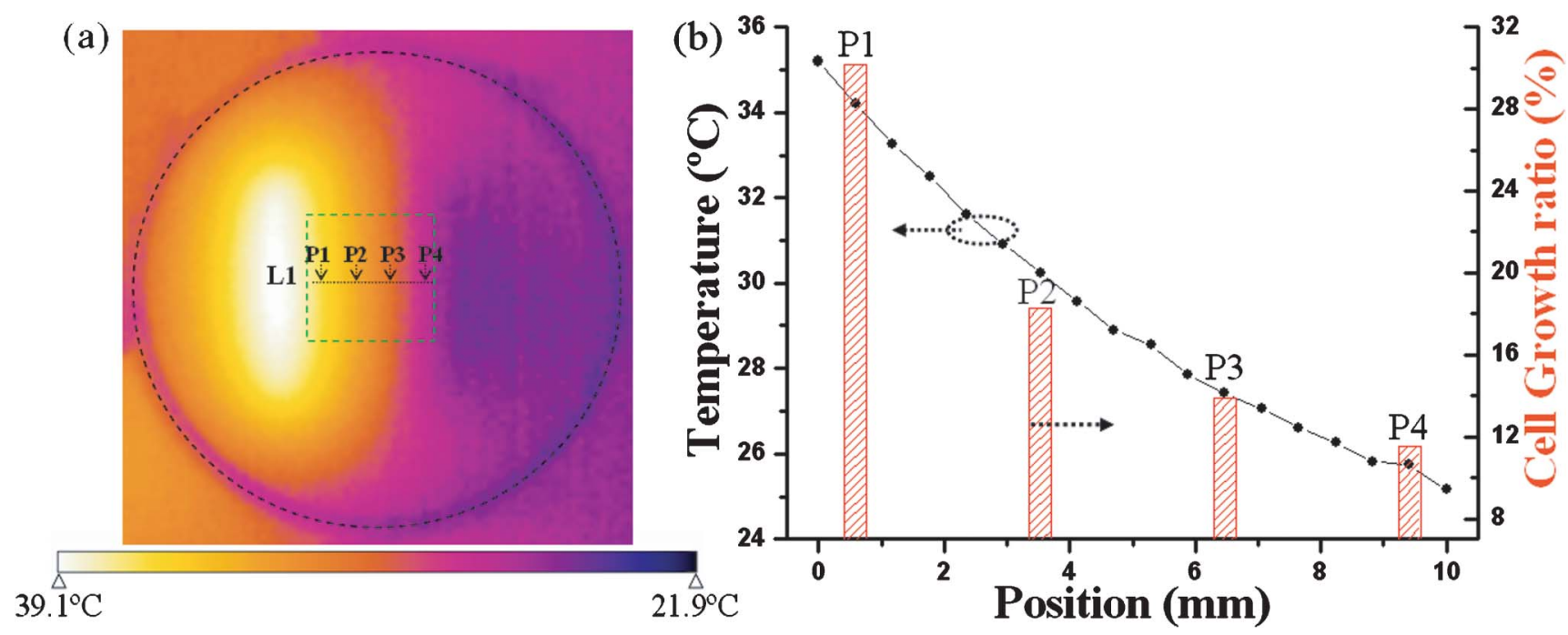

Fig. 4 (a) Infrared thermographic image of the culture dish was taken to show the thermal gradient. L1 stands for line 1. (b) Black curve: temperature as a function of position along L1 direction; Red histogram: cell growth ratio of four places (P1, P2, P3 and P4) as a function of position along L1. 


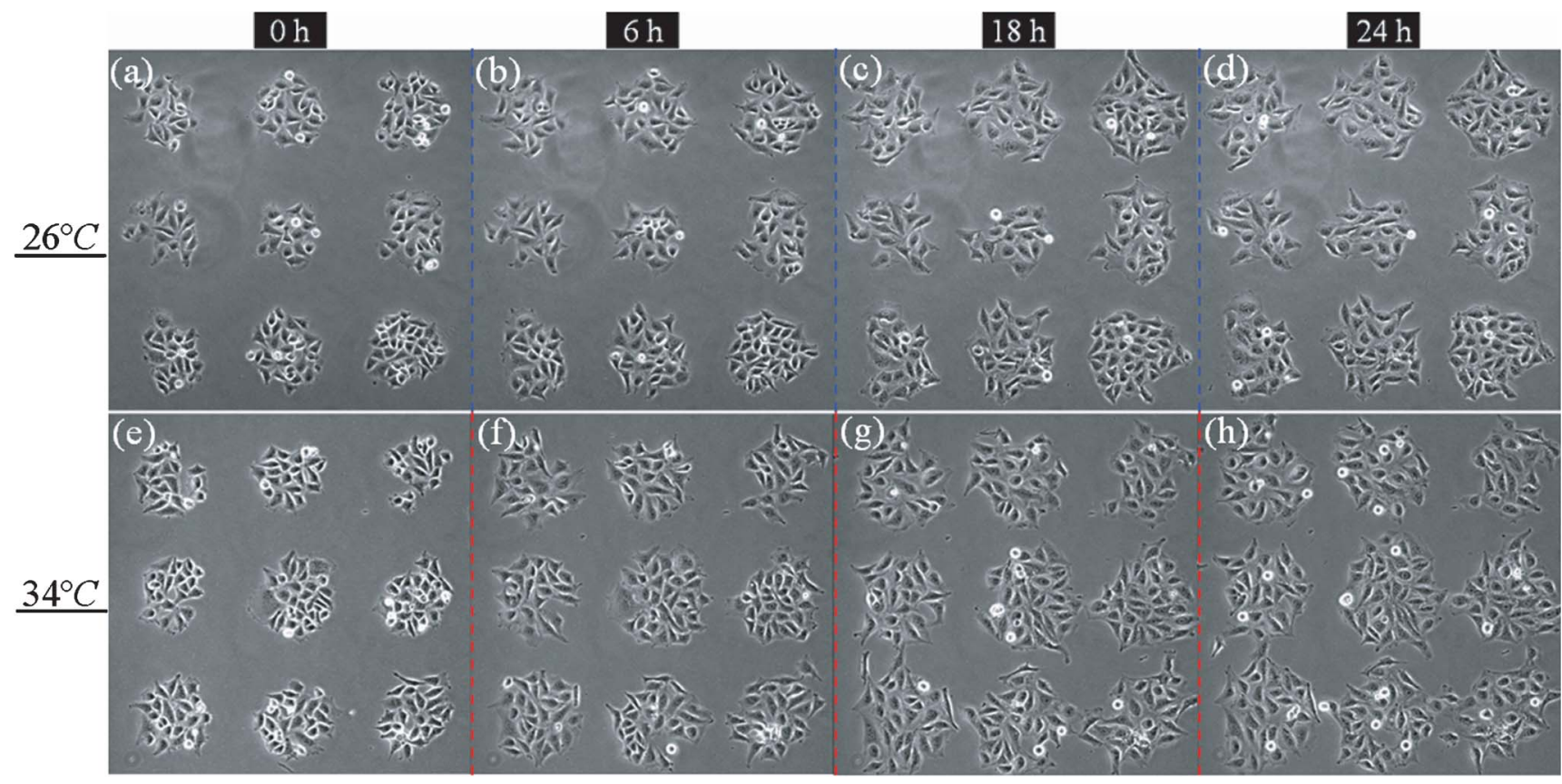

Fig. 5 Cell growth under thermal gradient. (a-d) at the same location of $26^{\circ} \mathrm{C} ;(\mathrm{e}-\mathrm{h})$ at the same location of $34{ }^{\circ} \mathrm{C}$. They are captured in the time of 0,6 , 18 , and $24 \mathrm{~h}$ after applied thermal gradient.

along $\mathrm{L} 1$ were measured and plotted in Fig. $4 \mathrm{~b}$ as a function of position, which data indicate that a reasonable and uniform temperature gradient was generated in the L1 direction. The temperature difference between the two ends, over a distance of $10 \mathrm{~mm}$, was about $10{ }^{\circ} \mathrm{C}$. The cell domains were subjected to this thermal gradient.

To evaluate the cell growth under the temperature gradient, we measured the cell number at four positions (P1, P2, P3 and P4 as marked in Fig. 4a) along L1 and calculated, over $24 \mathrm{~h}$, the cellgrowth ratio (CGR):

$$
C G R=\frac{N_{t_{1}}-N_{t_{0}}}{N_{t_{0}}} \times 100 \%,
$$

where $N_{t_{0}}$ is the cell number in nine domains in one image (see Fig. 5) at time $\mathrm{t}_{0}$, and $N_{t_{1}}$ is the cell number at the same position at time $t_{1}$. The results are plotted in Fig. $4 b$ (the red histogram) as a function of their positions along L1 axis. In the histogram and the L1 curve, the CGR seems to present the same trend as the temperature gradient: a decline as the position moves. Fig. 5 shows phase-contrast images of the cell array at two of fours positions: at $26^{\circ} \mathrm{C}(\mathrm{P} 4, \mathrm{a}-\mathrm{d})$, and $34{ }^{\circ} \mathrm{C}(\mathrm{P} 1, \mathrm{e}-\mathrm{h})$. The temperatures were estimated according to their positions in the L1 curve and the images were captured $0,6,18$, and $24 \mathrm{~h}$ after the thermal gradient was applied. In Fig. 5, the effect of the gradient on cell growth after $24 \mathrm{~h}$ is clear: the cell domains are still isolated from each other at the lower temperature, whereas at the higher temperature, they begin to connect via cell bridges. Although we observed the CGR at only four positions (or temperatures) over $24 \mathrm{~h}$, our result confirms that the thermal gradient made an effective impact on the cell growth and, furthermore, that our integrated device is suitable for long-term cell cultures. Additionally, since the cell-free region can be considered as a wound, a cell pattern could be used to mimic wound healing in vitro. Wound-healing assays could be high-throughput screened at different temperatures in one culture dish.

\section{Conclusions}

In summary, we successfully developed a convenient, efficient cellpatterning methodology using a Si-stencil with wide potential applications. The Si-stencil offers the advantages of easy handling, mature fabrication technologies, and hydrophilic surface and could be recovered by either a dry or wet cleaning method. Si-stencils with $\mathrm{D}_{\mathrm{h}}$ in the 8-400 $\mu \mathrm{m}$ range were fabricated and tested with HeLa cells. Cell pattern results indicated that the Si-stencil can be used from large-scale to single-cell manipulation. Furthermore, a cell array obtained by the Si-stencil was used to investigate cell growth under temperature gradient. Our results guarantees further applications in tissue engineering, biosensors and high-throughput screening. One such application is a high-throughput cell-based assay, which has attracted great interest for its reduction of screening costs incurred in the drug discovery process. ${ }^{30}$

\section{Acknowledgements}

This work is supported by Hong Kong RGC grant HKUST 604710 and research grant RPC10SC01, respectively.

\section{References}

1 S. R. Khetani and S. N. Bhatia, Nat. Biotechnol., 2008, 26, 120-126.

2 C. J. Bettinger and J. T. Borenstein, Soft Matter, 2010, 6, 4999-5015.

3 A. Khademhosseini, R. Langer, J. Borenstein and J. P. Vacanti, Proc. Natl. Acad. Sci. U. S. A., 2006, 103, 2480-2487.

4 P. Domachuk, K. Tsioris, F. G. Omenetto and D. L. Kaplan, Adv. Mater., 2010, 22, 249-260.

5 S. Y. Yoo, W. -J. Chung, T. H. Kim, M. Le and S. -W. Lee, Soft Matter, 2011, 7, 363-368

6 S. Sugiura, J. -i. Edahiro, K. Kikuchi, K. Sumaru and T. Kanamori, Biotechnol. Bioeng., 2008, 100, 1156-1165.

7 D. Wright, B. Rajalingam, S. Selvarasah, M. R. Dokmeci and A. Khademhosseini, Lab Chip, 2007, 7, 1272-1279. 
8 M. A. Cole, N. H. Voelcker, H. Thissen and H. J. Griesser, Biomaterials, 2009, 30, 1827-1850.

9 A. Offenhäusser, S. Böcker-Meffert, T. Decker, R. Helpenstein, P. Gasteier, J. Groll, M. Möller, A. Reska, S. Schäfer, P. Schulte and A. Vogt-Eisele, Soft Matter, 2007, 3, 290-298.

10 M. Nakamura, A. Kobayashi, F. Takagi, A. Watanabe, Y. Hiruma, K. Ohuchi, Y. Iwasaki, M. Horie, I. Morita and S. Takatani, Tissue Eng., 2005, 11, 1658-1666.

11 P. Calvert, Science, 2007, 318, 208-209.

12 L. H. Jin, B. Y. Yang, L. Zhang, P. L. Lin, C. Cui and J. Tang, Langmuir, 2009, 25, 5380-5383.

13 K. Y. Suh, J. Seong, A. Khademhosseini, P. E. Laibinis and R. Langer, Biomaterials, 2004, 25, 557-563.

14 Y. Tsuda, A. Kikuchi, M. Yamato, A. Nakao, Y. Sakurai, M. Umezu and T. Okano, Biomaterials, 2005, 26, 1885-1893.

15 C. D. McFarland, C. H. Thomas, C. DeFilippis, J. G. Steele and K. E. Healy, J. Biomed. Mater. Res., 2000, 49, 200-210.

16 D. Wlodkowic, S. Faley, M. Zagnoni, J. P. Wikswo and J. M. Cooper, Anal. Chem., 2009, 81, 5517-5523.

17 I. Inoue, Y. Wakamoto, H. Moriguchi, K. Okano and K. Yasuda, Lab Chip, 2001, 1, 50-55.

18 D. D. Carlo, L. Y. Wu and L. P. Lee, Lab Chip, 2006, 6, 1445-1449.
19 D. Wright, B. Rajalingam, J. M. Karp, S. Selvarasah, Y. Ling, J. Yeh, R. Langer, M. R. Dokmeci and A. Khademhosseini, J. Biomed. Mater. Res., Part A, 2008, 85, 530-538.

20 C. H. Cho, J. Park, A. W. Tilles, F. Berthiaume, M. Toner and M. L. Yarmush, BioTechniques, 2010, 48, 47-52.

21 Y. Jimbo, H. P. C. Robinson and A. Kawana, IEEE Trans. Biomed. Eng., 1993, 40, 804-810.

22 K. Atsuta, H. Noji and S. Takeuchi, Lab Chip, 2004, 4, 333-336.

23 E. Ostuni, R. Kane, C. S. Chen, D. E. Ingber and G. M. Whitesides, Langmuir, 2000, 16, 7811-7819.

24 Y. Zheng, W. Dai, D. Ryan and H. Wu, Biomicrofluidics, 2010, 4, 036504.

25 A. Folch, B. -- Jo, O. Hurtado, D. J. Beebe and M. Toner, J. Biomed. Mater. Res., 2000, 52, 346-353.

26 C. -H. Hsieh, C. -J. C. Huang and Y. -Y. Huang, Biomed. Microdevices, 2010, 12, 897-905.

27 N. A. Raof, W. K. Raja, J. Castracane and Y. Xie, Biomaterials, 2011, 32, 4130-4139.

28 M. Yamato, C. Konno, M. Utsumi, A. Kikuchi and T. Okano, Biomaterials, 2002, 23, 561-567.

29 M. A. Shoffner, J. Cheng, G. E. Hvichia, L. J. Kricka and P. Wilding, Nucleic Acids Res., 1996, 24, 375-379.

30 M. -Y. Lee and J. S. Dordick, Curr. Opin. Biotechnol., 2006, 17, 619-627. 